\title{
Modified Selective Non-Catalytic Reduction System to Reduce NOx Gas Emission in Biodiesel Powered Engines
}

\author{
K. Masera \\ Mechanical Engineering and Design \\ Aston University, Birmingham, UK \\ e-mail:k.masera2@aston.ac.uk \\ A. K. Hossain* \\ Mechanical Engineering and Design \\ Aston University, Birmingham, UK \\ e-mail: a.k.hossain@aston.ac.uk
}

\begin{abstract}
Biodiesel is considered as one of the attractive alternatives to fossil diesel fuel. Although biodiesels reduces most of the harmful gas emissions, they normally releases higher NOx emissions compared to fossil diesel. The Selective Catalytic Reduction (SCR) is a wellknown technique used in the OEM industry to mitigate NOx emission. However, this technique may not be suitable for application in low power density engines due to back pressure and clogging issues. On the other hand, Selective Non-Catalytic Reduction (SNCR) is used in relatively large combustion operations ie. boilers and incinerators. The main disadvantage of SNCR technique is the high temperature window for diesel engine exhaust temperature. This study introduces a new design concept, which is a combination of SCR and SNCR systems, for low power density diesel engines. The developed after-treatment system composed of two main parts, injection-expansion pipe and swirl chamber. The working principle is providing maximum mixing of the injected fluid and exhaust gas in the expansion chamber, then creating a maximum turbulence in the swirl chamber. In this regard, NOx emission can be reduced at relatively lower exhaust temperatures without using any catalyst. The CFD models of three design candidates were examined in terms of velocity magnitudes, turbulence intensity and particle residence time to select the optimum physical dimensions. The selected design was manufactured and installed to exhaust system of a 1.3 litre diesel engine. Two fluids distilled water and urea-water solution were injected separately at the same flow rate of $375 \mathrm{ml} / \mathrm{min}$. Exhaust gas emissions of fossil diesel, sheep fat biodiesel waste cooking oil biodiesel blend and chicken fat - cottonseed biodiesel blend were tested. No significant changes in $\mathrm{CO}_{2}$ and $\mathrm{HC}$ emissions were observed. However, it was found that distilled water injection reduced $\mathrm{CO}$ and $\mathrm{NO}$ emissions by about $10 \%$ and $6 \%$ for fossil diesel; and by about $9 \%$ and $7 \%$ for biodiesels operation respectively. The urea-water injection led to reductions in CO and NO emissions by about $60 \%$ and $13 \%$ for fossil diesel; and by about $45 \%$ and $15 \%$ for biodiesels respectively.
\end{abstract}

\section{KEYWORDS}

Biodiesel, after-treatment, NO emission, CI Engine, NOx control, combustion, exhaust emissions

\footnotetext{
${ }^{*}$ Corresponding author
} 


\section{INTRODUCTION}

The biodiesels are viable alternatives to replace fossil diesel [1, 2]. They are renewable, biodegradable, carbon neutral, energy efficient and can be used in compression ignition (CI) engines without any modification [2]. In addition, most of the exhaust gas emissions such as $\mathrm{CO}, \mathrm{CO}_{2}, \mathrm{HC}$ and smoke intensity are reduce with biodiesels compared to fossil diesel $[3,4]$. However, NOx emissions of in biodiesels operation are reported to be comparable or slightly higher relative to diesel operation [5]. According to Thangaraja et al [6], 85\% of the published literature reported that NOx emission was increased for biodiesel powered CI engines, while only about $10 \%$ of the literature reported no change in NOx gas emission compared to diesel. Interestingly, only $5 \%$ of the literature found NOx reduced with biodiesels. The reason underlies on the increased combustion temperature as a result of the higher oxygen content of biofuels which provides improved combustion. Therefore, it is decided to cope with the NOx penalty at the exhaust system by a help of after treatment system.

In this regard, the latest technology found is ammonia injection after the combustion process i.e. at the exhaust system [7]. One application of this technique is Selective Non-Catalytic Reduction (SNCR) which generally used in relatively large engines, furnaces, incineration or boilers. SNCR system injects diesel exhaust fluid (DEF - ammonia) directly into the exhaust system without any catalyst. Another application is Selective Catalytic Reduction (SCR) which also involves catalytic to upgrade the NOx reduction yield. Because of the cost of catalyst, it is mainly used in relatively small size applications such as the automotive sector.

The SCR was first found in the 1970s and commercialised in Japan around 1957 [8]. The operational temperature of the system is reported above $350^{\circ} \mathrm{C}$ [9]. Literature reported $\mathrm{NOx}$ reductions of up to $90 \%$ with the application of SCR after treatment system [10]. However, these extreme NOx mitigations came up with well-developed designs providing controlled $\mathrm{NH}_{3}$ to NOx ratio and uniform velocity through the catalyst [10]. Even though SCR is a very effective technique, there are some drawbacks due to the presence of a catalyst such as erosion (because of dust or ammonium bisulphate), limited lifetime, mass transfer, expense and possibility of catalytic disintegration which cause an additional source of pollutant $[8,11,12]$. These problems can be avoided with SNCR system which is free of catalyst. However, SNCR systems have the operating temperature between $875^{\circ} \mathrm{C}$ and $1050^{\circ} \mathrm{C}$, thus they are mainly used in large stationary units like boilers, furnaces and incineration [13]. This is mainly due to the lower reaction rate between ammonia and $\mathrm{NOx}$ below $800^{\circ} \mathrm{C}$; hence the injected ammonia does not properly react with the exhaust gas. On the other hand, above $1200^{\circ} \mathrm{C}$ temperature, ammonia oxidises and starts forming NO which increases the emissions [14]. Mansha et al, [15] proved these conditions with a numerical study. They studied NOx reduction by utilising SNCR technique and predicted up to $96 \%$ reduction of thermal NOx under the conditions of; molar ratio of 1 ; the temperature at $800^{\circ} \mathrm{C}$ and residence time 2.5 seconds [15]. The major barrier of SNCR technique for diesel engine application is the hightemperature window (i.e. operation range between $875^{\circ} \mathrm{C}$ and $1050^{\circ} \mathrm{C}$ ) [16]. To avoid this issue, studies have tried various solutions such as implementing an extra mixing chamber to enhance the turbulence [17], double compression expansion engines to increase the exhaust temperature [16], various additives and/or injection agents [18] and injecting aqueous urea solution directly into the combustion chamber after the fuel injection [19]. For example, Thiyagarajan et al., [17] studied SNCR technique with an extra mixing chamber on a single cylinder CI engine on diesel operation. They have tested four different injection agents which were anhydrous ammonia, succinic acid, diethylamine and monoethanolamine at $1 \mathrm{~kg} / \mathrm{h}$ flow rate. They reported maximum reductions of $10 \%$ and $15 \%$ for $\mathrm{NO}$ and $\mathrm{CO}_{2}$ emissions with 
monoethanolamine injection at full load. Muric et al., [16] used double compression expansion engine and reported 55\% reduction on NOx emission at $1200 \mathrm{rpm}$ and $1200 \mathrm{~K}$ temperature. However, the same study also provided $10-22 \%$ NOx reduction at $1000 \mathrm{~K}$ exhaust temperature. In another study, Krahl et al., [18] tested 1,2,3-tris(diethylaminomethoxy)propane, 1,2-Bis-(diethylaminomethoxy)-3-ter/-butoxy propane and 2,2-dimethyl-(4-diethylaminomethoxy)-1,3-dioxolane additives with SNCR and obtained $22 \%$ NOx reduction for diesel and 47\% NOx reduction for biodiesel. Yang et al., [19] used a separate injector to inject urea-water solution directly into the combustion chamber during the power stroke, they reported NOx reduction up to about $53 \%$.

Based on the literature review, three parameters such as mixing (turbulence), exhaust temperature and residence time are found critical for SNCR efficiency. Therefore, the aim of this study is to design and test a novel SNCR after treatment system for CI engine application with a special emphasis on NOx reduction. By this means, NOx penalty of biodiesels will be lowered and catalytic problems of SCR will be avoided. The new design is composed of two parts which are expansion and swirl chambers. Enhanced turbulence intensity and residence time are desired to improve NOx reduction of biodiesel as well as diesel. The CFD analysis of design options is carried out to select the best design geometry in terms of turbulence intensity and injected particle residence time. Then, the selected design was manufactured and implemented on the test rig for experimental analysis. The objectives of the current study are: (i) to select after treatment system components which will maximise the turbulence and residence time, (ii) to select an optimum concept and dimensions through CFD modelling and, (iii) to implement and test the after treatment system on the compression ignition (CI) engine fuelled with biodiesels. The biodiesels used in this study was mixture of waste cooking oil biodiesel and sheep fat biodiesel at 50/50 volume fraction (W50A50); and cottonseed oil biodiesel and chicken fat biodiesel mixture at 50/50 volume fraction (CO50CH50). A multicylinder indirect injection engine was used in the study.

\section{METHODOLOGY}

\section{NOx decomposition reaction mechanism}

Ammonia is a well-known chemical that reacts with nitrogen oxides and forms nitrogen and water which are not harmful. However, ammonia itself is a dangerous chemical. Therefore, it is commonly stored and transferred in the form of urea $\mathrm{CO}\left(\mathrm{NH}_{2}\right)_{2}$. Typically, urea-water solution is used for injection through after treatment systems. Then the urea decomposes into ammonia in the presence of water as shown in equation 1 [20]. This process takes place above $350^{\circ} \mathrm{C}$ with a residence time minimum of $0.1 \mathrm{~s}$ [20].

$$
\mathrm{CO}\left(\mathrm{NH}_{2}\right)_{2}+\mathrm{H}_{2} \mathrm{O} \rightarrow 2 \mathrm{NH}_{3}+\mathrm{CO}_{2}
$$

The three possible reaction mechanisms of NOx reduction in the presence of ammonia are illustrated in equations 2,3 and 4 [20-23].

$$
\begin{aligned}
& 4 \mathrm{NH}_{3}+4 \mathrm{NO}+\mathrm{O}_{2} \rightarrow 4 \mathrm{~N}_{2}+6 \mathrm{H}_{2} \mathrm{O} \\
& 4 \mathrm{NH}_{3}+2 \mathrm{NO}_{2}+\mathrm{O}_{2} \rightarrow 3 \mathrm{~N}_{2}+6 \mathrm{H}_{2} \mathrm{O} \\
& 2 \mathrm{NH}_{3}+\mathrm{NO}_{2}+\mathrm{NO} \rightarrow 2 \mathrm{~N}_{2}+3 \mathrm{H}_{2} \mathrm{O}
\end{aligned}
$$


The required amount of urea for an application can be calculated through the introduced equations. In this research, it was assumed that all $\mathrm{NO}$ will be converted through equation 2 and all $\mathrm{NO}_{2}$ will be converted through equation 3 . The equation 4 was not considered as it also requires the same molar ratio with the equations 2 and 3 ( 2 moles of $\mathrm{NH}_{3}$ is required to convert 1 mole of $\mathrm{NO}_{2}$ and 1 mole of $\mathrm{NO}$ ). Ultimately, 1 mole of $\mathrm{NH}_{3}$ is needed to decompose 1 mole of $\mathrm{NO}$; and 2 moles of $\mathrm{NH}_{3}$ is required for decomposing 1 mole of $\mathrm{NO}_{2}$.

\section{Injection flow rate}

Although the rated speed of the engine was $1500 \mathrm{rpm}$, the after-treatment system was tested at $2000 \mathrm{rpm}$ and $80 \%$ engine load $(11.2 \mathrm{~kW})$. This was simply because to meet the exhaust temperature limitations of the low power density engine. The exhaust temperature was around $380{ }^{\circ} \mathrm{C}$ at the mentioned condition. Exhaust heat wrap also applied to retain the heat at the exhaust pipe.

The $\mathrm{NO}$ and $\mathrm{NO}_{2}$ emissions for the biodiesel were previously measured as $1.408 \mathrm{~g}$ and 0.840 $\mathrm{g}$ through Horiba gas analyser. Considering these emissions, approximately $1.4 \mathrm{~g}$ of ammonia per second is required to be injected at the exhaust pipe. This corresponds to around $2.2 \mathrm{~g}$ of urea. The commercial Diesel Exhaust Fluids (DEF - AdBlue) are generally composed of $\% 32.5$ urea solution in deionised water. As a commercially available DEF was used in this study, the flow rate of the $\% 32.5$ urea solution in deionised water was calculated as 308 $\mathrm{ml} / \mathrm{min}$.

\section{Design concepts}

Three exhaust after treatment geometries were developed and modelled in ANSYS FLUENT software version 17.1 to figure out the best geometry Figure 1. The idea of the system was to inject the commercially available urea-water solution (AdBlue) but avoiding the catalytic; as the use of catalytic cannot be suitable for low power density engines which cannot cope with high back pressures. In this regard, it was planned to increase both turbulence intensity and particle residence time of the catalytic free system.
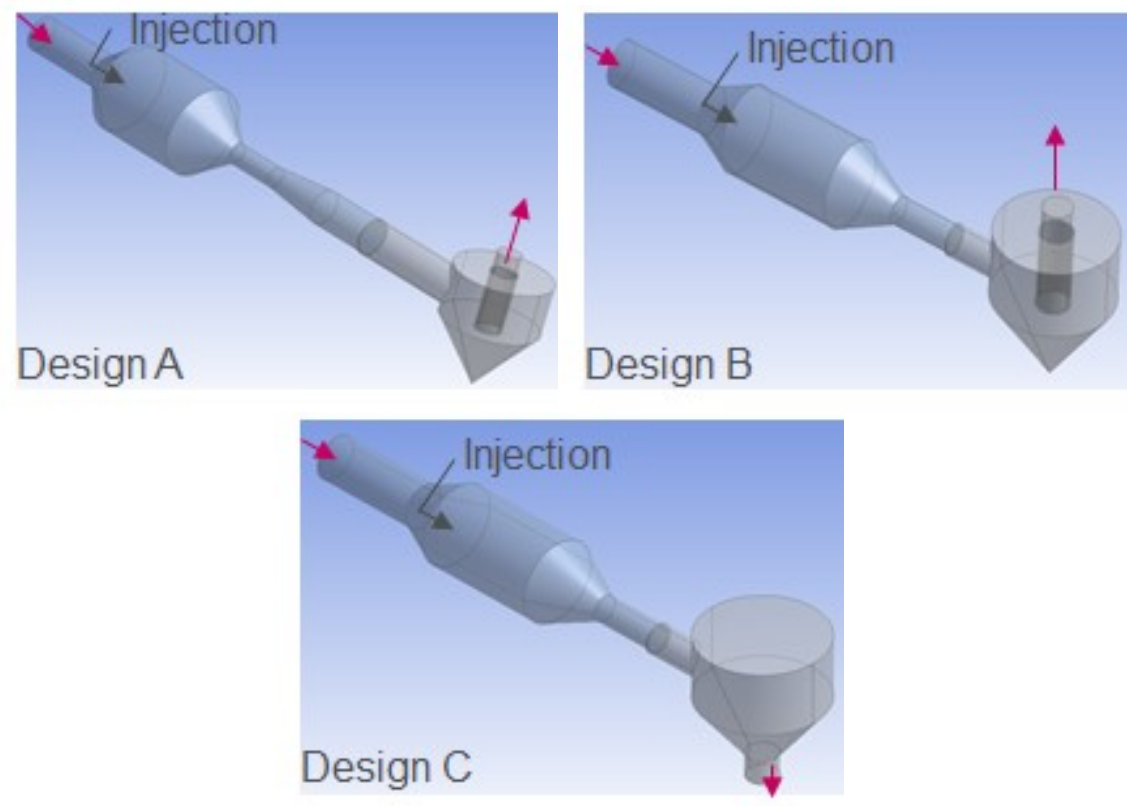

Figure 1. Design candidates tested in CFD modelling; design A, design B and design C 
All three designs were composed of two parts which were named injection and expansion pipe and swirl chamber. The injection point was at the axis of the injection and expansion pipe and located just before the expansion section. In this regard, mixing between injected fluid and exhaust gas can be enhanced through the expansion pipe. More specifically, injection fluid molecules will enter the exhaust system whilst the diameter of the pipe is increasing, thus the gap between exhaust molecules also be enlarged and filled with the injected agent. Then, the diameter will again be reduced to increase the velocity before flowing into the swirl chamber, where the turbulence intensity was desired to increase.

The design A had larger expansion pipe diameter, compared to designs $\mathrm{B}$ and $\mathrm{C}$. In addition, its exit diameter was the same as the inlet diameter. In contrast, designs B and $\mathrm{C}$ had the same injection and expansion pipe dimensions which has smaller exit diameter than exit diameter. The designs A and B had the same swirl chamber with an exit from the top of the chamber. Moreover, the exit pipe extends deep into the chamber, forces the entering exhaust fluid to rotate around it by flowing down (towards the conical part), then flowing towards upside through inside of the exit pipe. By this manner, not only the turbulence intensity but also residence time was desired to improve. On the other hand, the swirl chamber of design $\mathrm{C}$ had an exit from the bottom (conical part) of the chamber.

\section{Meshing}

The numbers of cells were 492692, 505591 and 485258; and the numbers of nodes were 303136, 265173 and 278201 for designs A, B and C, respectively. Figures 2, 3 and 4 show the meshing for design concepts. Although more accurate results could be achieved with higher meshing size, the results obtained from a similar order of magnitude meshing size would be acceptable [24]. Because the design candidates will only be compared to each other (in terms of turbulence intensity and residence time) to select the best option rather than investigating the NOx reductions.
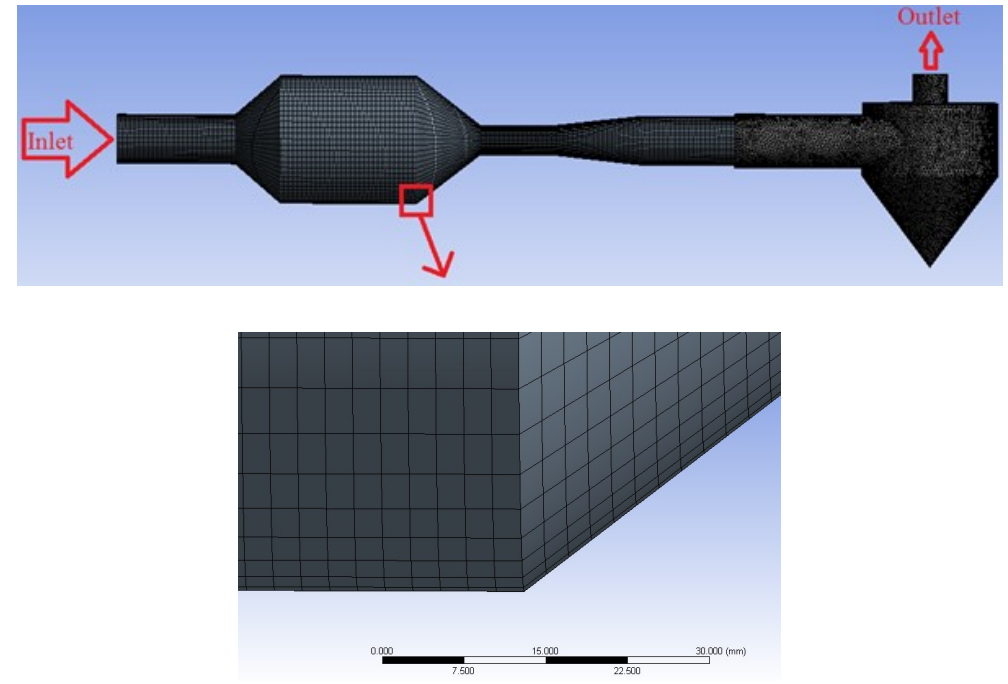

Figure 2. The meshing illustration of design A, which has a larger diameter expansion pipe and venturi between expansion pipe and swirl chamber 


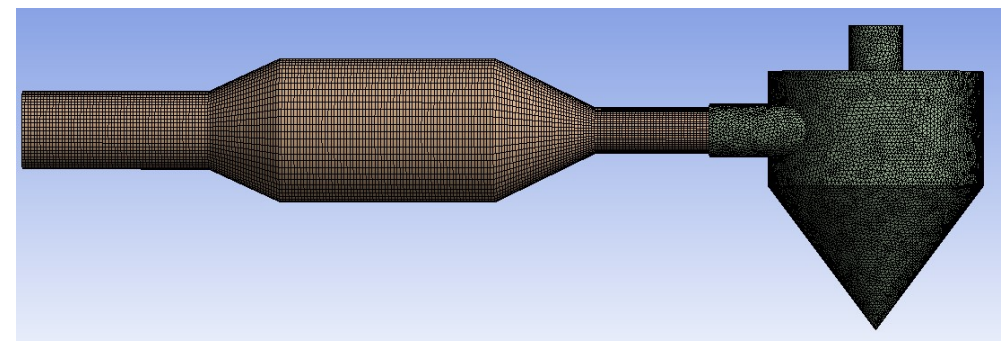

Figure 3. The meshing illustration of design B, which has no venturi between the expansion pipe and swirl chamber and outlet is on top of the swirl chamber.

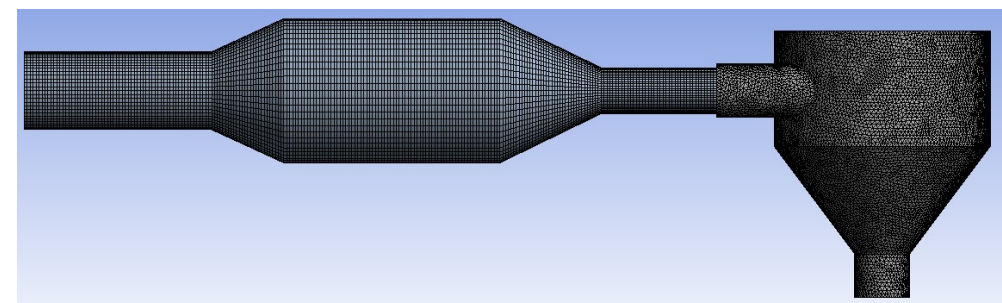

Figure 4. The meshing illustration of design $\mathrm{C}$, which has no venturi between the expansion pipe and swirl chamber and outlet is at the bottom of the swirl chamber

\section{CFD model set up}

This simulation was inspired from a CFD modelling for a study aimed for $\mathrm{CO}_{2}$ emission reduction by magnesium hydroxide injection [24]. All three designs were modelled through the same calculation process, turbulence algorithms and boundary conditions. The viscous RNG k-e, standard wall functions were selected to have the best monitoring on the turbulence motion [25]. In addition, swirl dominated flow option was selected as it was expected with the presence of the swirl chamber.

Three different species were selected for species model which were assumed as nitrogen oxide as a continuous phase (exhaust gas) and urea-water as a discrete phase. The other exhaust gases were neglected for the simplicity of the study. Nevertheless, the flow behaviour of the exhaust gas can be considered as a single-phase flow, hence neglecting other components was an acceptable assumption for the turbulence intensity and residence time analysis [24].

The discrete phase model was selected for simulating the injection of urea-water solution (AdBlue) into the exhaust gas stream. Interaction with the continuous phase was activated to simulate The evaporation of injection agent and momentum change between the two phases [24]. Then, the injection conditions such as location, direction, nozzle type, temperature, flow rate, injection angle and diameter were introduced to the model. The urea-water option was selected as injection material.

Inlet boundary condition was entered in accordance with the previous experimental measurements [3]. On the other hand, the outlet boundary condition was set as out flow. To provide the interaction between the walls and injected fluid, wall-jet was property was activated. Gravity was also introduced to the model for realistic simulation. 
SIMPLE scheme was used for the steady-state flow of pressure related equations; Least Squares Cell Based gradient was implemented for the selected mesh type and minimum false diffusion; PRESTO pressure for swirl flows involving pressure gradients; Second order upwind for more accurate results with Taylor series expansion of the cell-centred solution [24].

\section{CFD model outcomes and design selection}

Initially exhaust gas flow was solved without any injection. Then, the injection was implemented too. The system was successfully converged. As discussed earlier, the most important parameters are the turbulence intensity and particle residence time for this selection. The velocity magnitude and turbulence intensities for the design candidates were plotted through velocity vectors and presented in Figure 5. The magnitude scales were arranged the same for all three candidates, hence colour maps of velocity vectors indicate magnitudes of velocity and turbulence intensity. According to results, design A gave much lower velocity and turbulence than designs $\mathrm{B}$ and $\mathrm{C}$, thus design $\mathrm{A}$ can be eliminated at this stage. However, no significant difference was spotted between designs B and C.

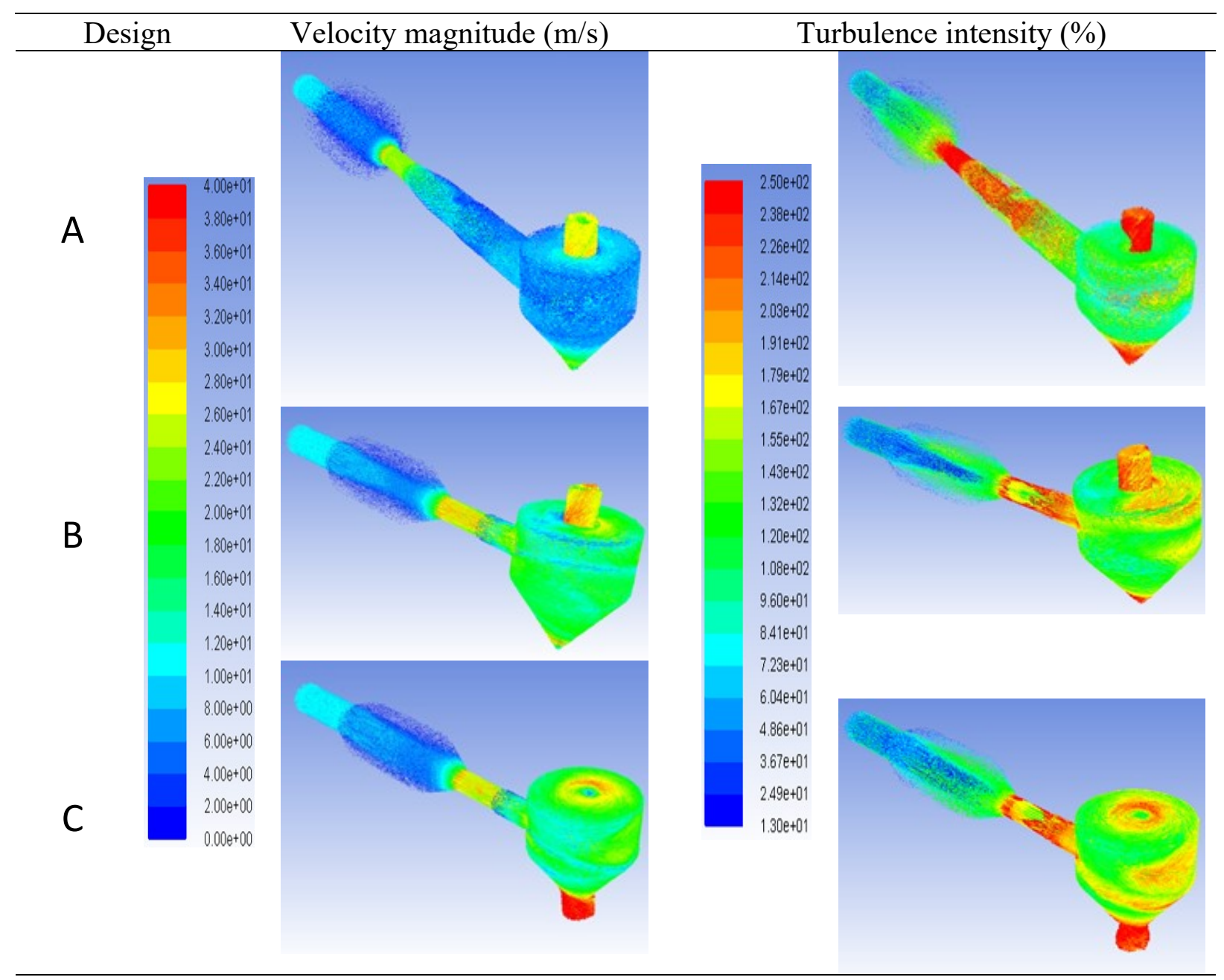

Figure 5. Comparison of design candidates A, B and C in terms of velocity magnitude and turbulence intensity 
Design A was eliminated for lower velocity and turbulence, thus designs $\mathrm{B}$ and $\mathrm{C}$ were compared in terms of particle residence time in Figure 6. The residence time results of design $\mathrm{B}$ and $\mathrm{C}$ were again comparable at the expansion pipe. However, residence times of the design $\mathrm{B}$ and design $\mathrm{C}$ were recorded as 3 seconds and 1 second at the swirl chamber, respectively. Consequently, design $\mathrm{B}$ was superior to other candidates when all parameters were considered. Therefore, design $\mathrm{B}$ was selected to manufacture and conduct the experiment.

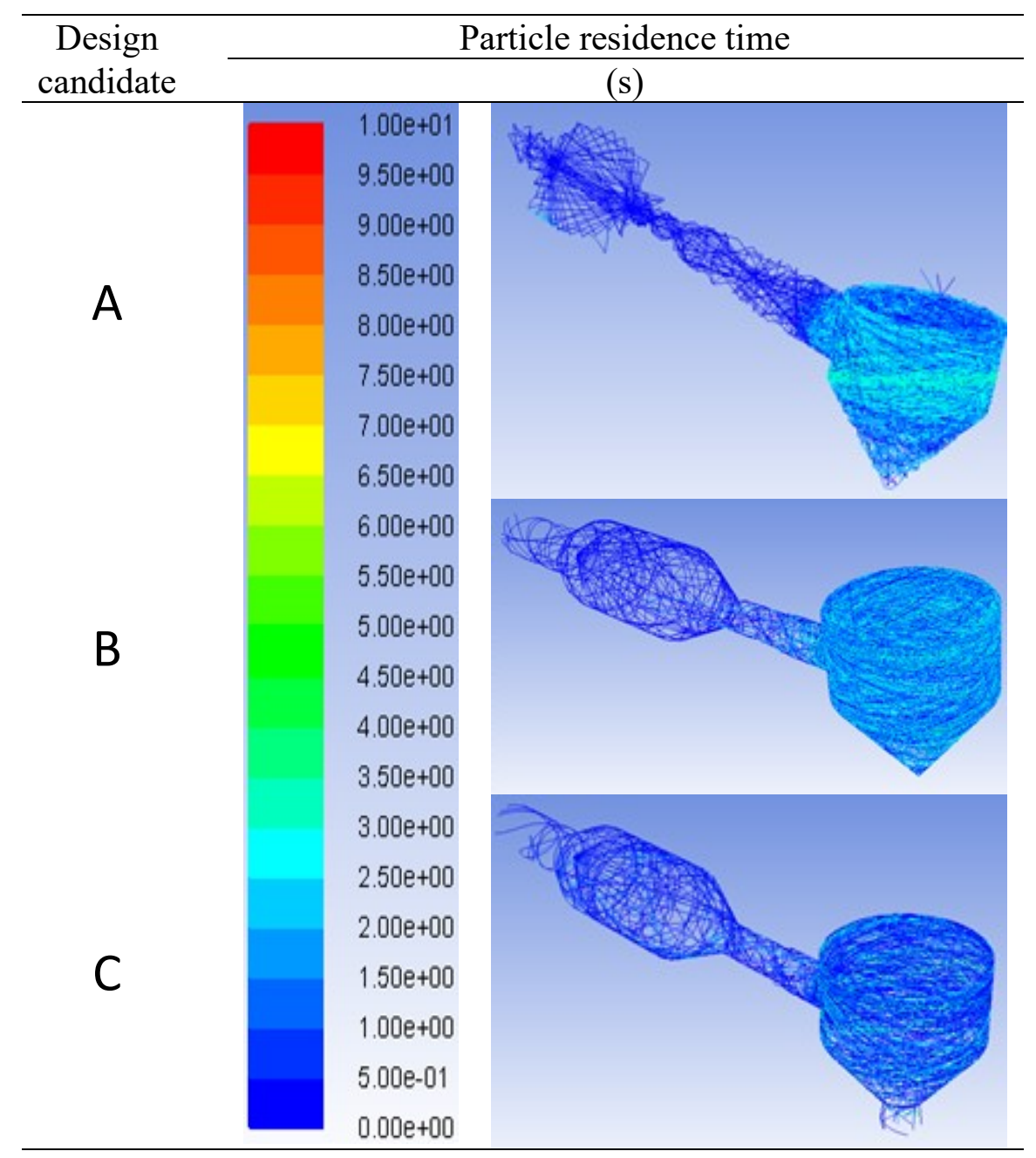

Figure 6. Comparison of design candidates A, B and C in terms of particle residence time

\section{Experimental investigation of the aftertreatment system}

The selected design was manufactured at the duRose Ltd metalwork company in Birmingham. A small water pump and cone injector were used to develop an injection mechanism for the modified SNCR system Figure 7. The flow rate was measured by the stopwatch-bucket method and the lowest flow rate of $375 \mathrm{ml} / \mathrm{min}$ was adjusted by providing 3 volts to the pump. Although this value was higher than the calculated value, it was used in the experiment as the $\mathrm{NH}_{3}$ slip was out of the scope for this analysis. 


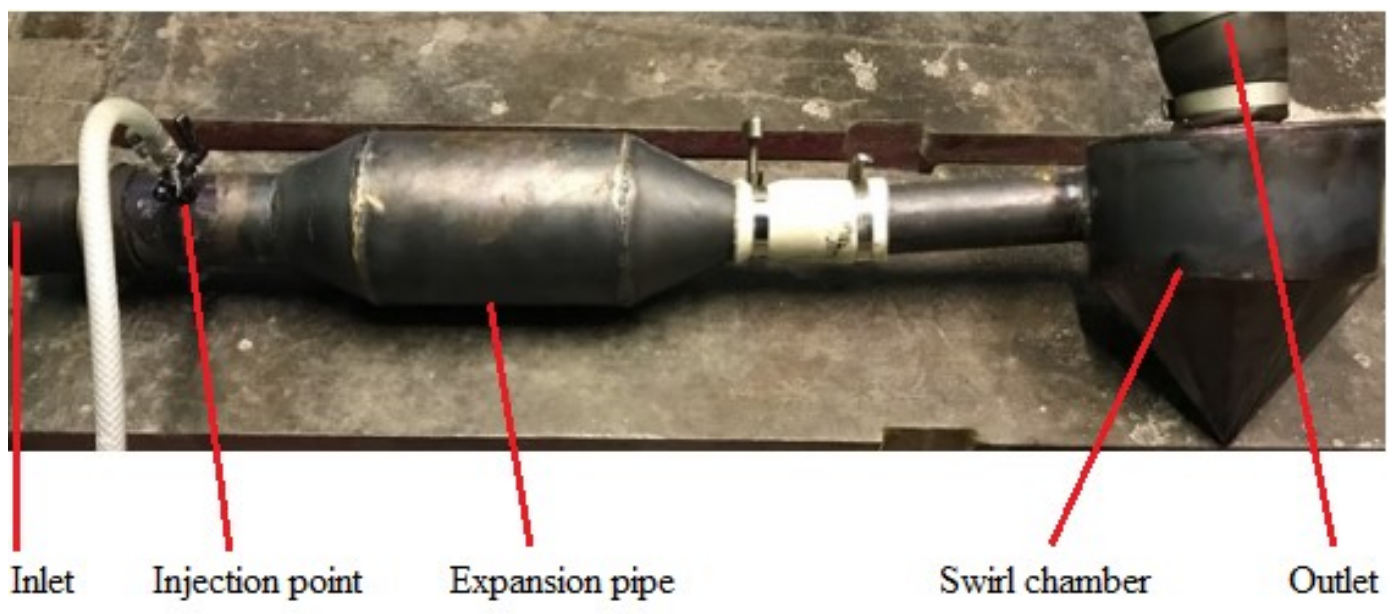

Figure 7. The modified SNCR aftertreatment system assembly

Next, the injector was located into the injection pipe and the flow of the pattern was checked before installing the system on the test rig Figure 8.

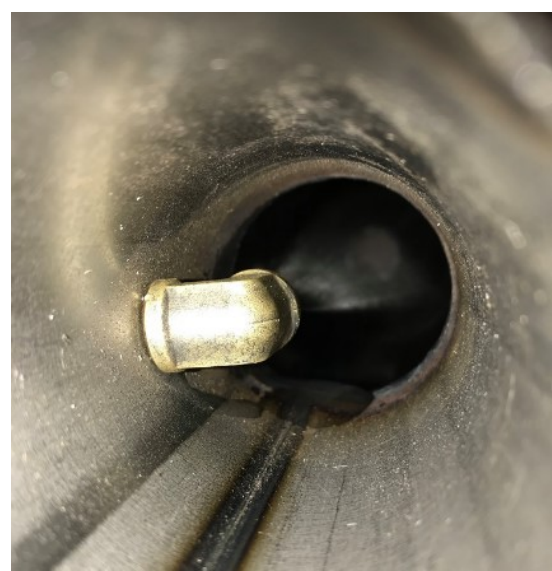

Figure 8. Injection pattern starts just before the expansion pipe and expands along with the pipe

The setup was installed on the exhaust system as shown in Figure 9. The national grid power converted into direct current and 3 volts supplied to the pump to reduce the flow rate. The expansion pipe was placed parallel to the ground and the exit of the swirl chamber was located vertically as simulated. The injection was controlled by the on-off switch of the power source. The system was commissioned by a leak test. Moreover, the in-cylinder pressure diagram was checked for any indication of abnormalities due to back pressure. Ultimately, the system was ready for the tests. 


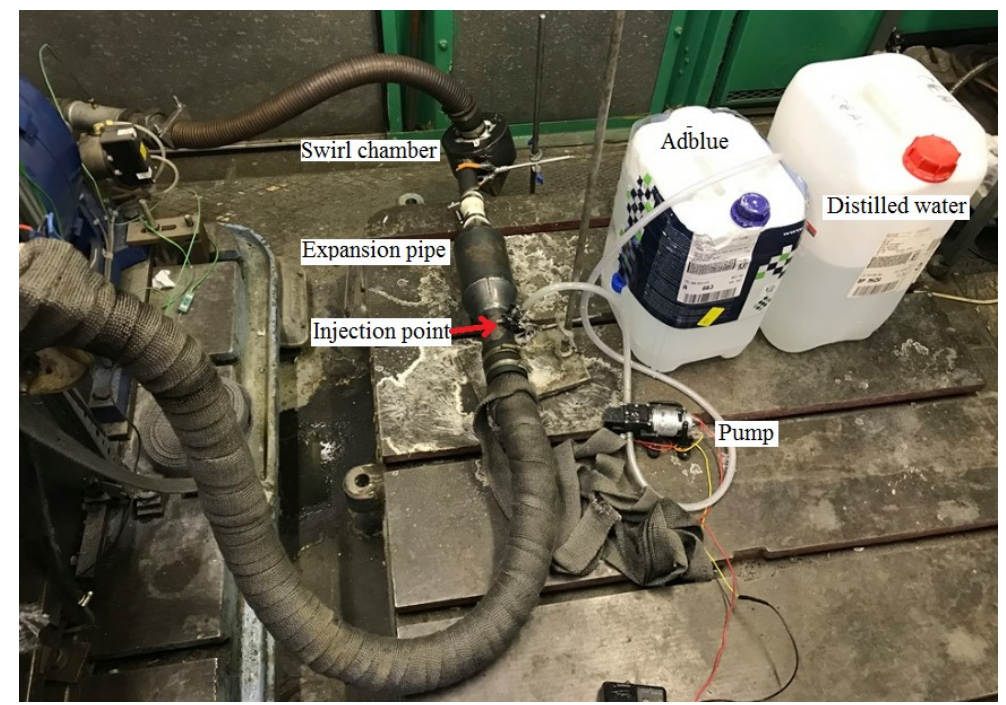

Figure 9. Engine test rig equipped with the modified SNCR after treatment system

\section{RESULTS AND DISCUSSION}

In-cylinder pressure diagrams are important to spot any abnormalities regarding the back pressure due to the implemented aftertreatment system [26]. Therefore, in-cylinder pressures of fossil diesel, W50A50 and CO50CH50 were measured at $2000 \mathrm{rpm}$ and at 80\% engine load with the modified SNCR system Figure 10. The results gave comparable results with each other such as 67 bars at $13^{\circ} \mathrm{CA}$. Moreover, the trends before and after the application of the modified SNCR system were also the same with each other and no abnormal peak or jump was spotted.

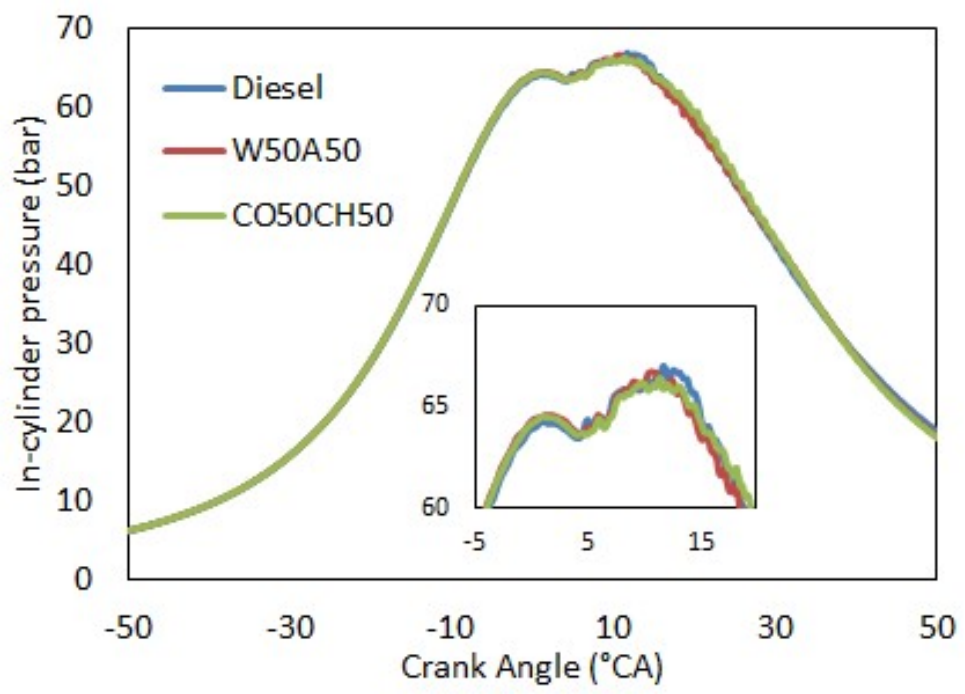

Figure 10. In-cylinder pressures for the test fuels with the modified SNCR aftertreatment system.

$\mathrm{CO}$ and $\mathrm{CO}_{2}$ emissions under no injection, neat distilled water injection and urea-water (AdBlue) injection were given in Figure 11 and 12, respectively. It was clear that there was no significant effect of neither neat water injection nor urea-water injection on $\mathrm{CO}$ and $\mathrm{CO}_{2}$ emissions. This was because there was not any diesel oxidation catalyst (DOC) or diesel 
particulate filter (DPF) facility on the test rig. However, $\mathrm{CO}$ emission was decreased slightly by around 0.006 volume $\%, 0.005$ volume $\%$ and 0.003 volume $\%$ with the urea-water injection for the diesel, W50A50 and $\mathrm{CO} 50 \mathrm{CH} 50$ respectively. CO reduction with urea-water injection was in good agreement with the literature. Praveen and Natarajan [27] also stated a $32 \%$ reduction with the urea injection for diesel-ethanol (90/10) blend and linked this reduction to oxidation of $\mathrm{CO}$ in the presence of excess oxygen. This also explains the slight increase in $\mathrm{CO}_{2}$ with urea-water injection.

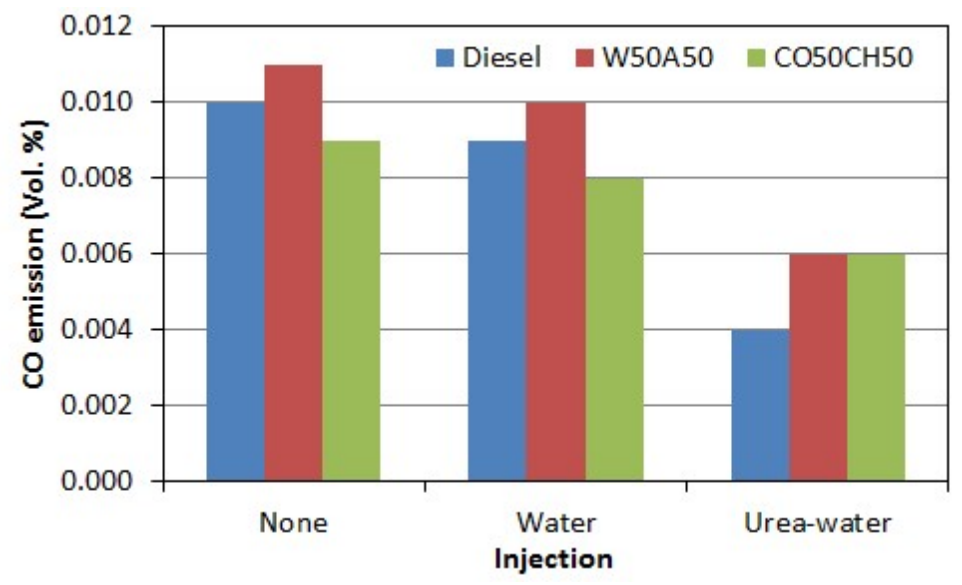

Figure 11. CO emissions of diesel, W50A50 and CO50CH50 with the modified SNCR application.

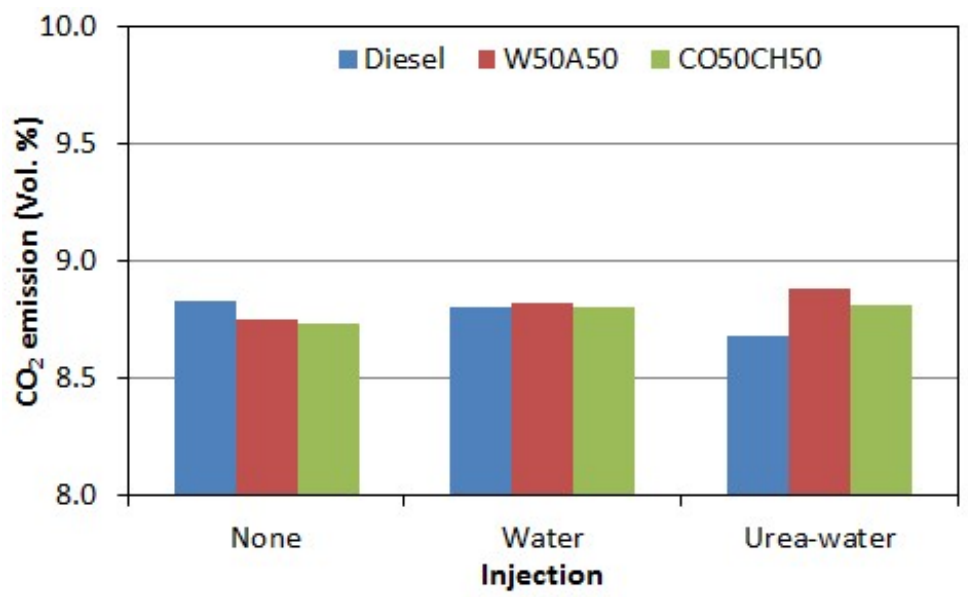

Figure 12. $\mathrm{CO}_{2}$ emissions of diesel, W50A50 and CO50CH50 with the modified SNCR application.

The unburned hydrocarbons emissions were also measured with and without injections Figure 13. The results were the same in all scenarios; hence HC was not affected by the modified SNCR system. This finding agreed with the literature $[17,20]$. 


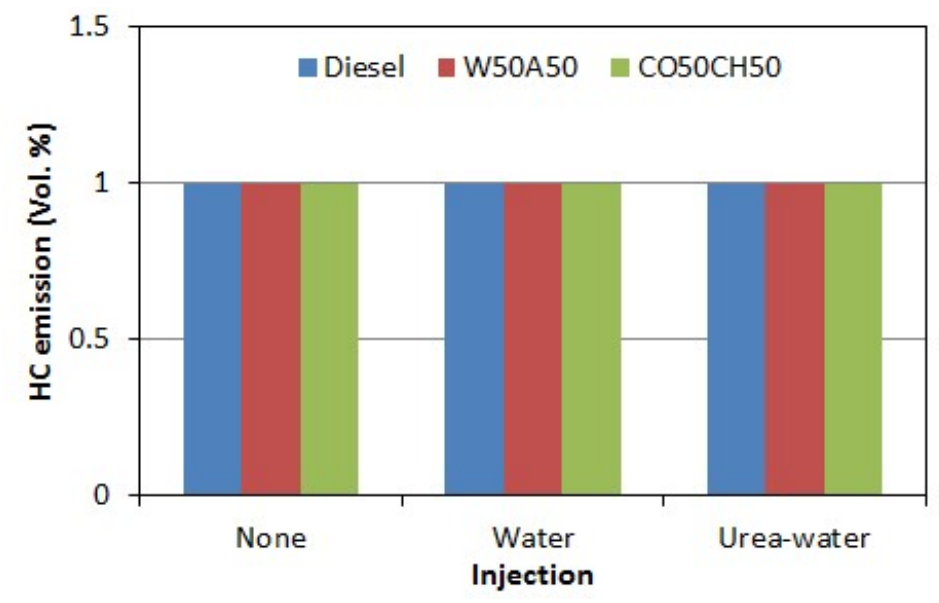

Figure 13. HC emissions of diesel, W50A50 and CO50CH50 with the modified SNCR application.

Figure 14 studies the NO emissions of diesel, W50A50 and CO50CH50 with and without modified SNCR after-treatment system. Without any injection, the biodiesels W50A50 and $\mathrm{CO} 50 \mathrm{CH} 50$ gave similar NO emission (at $2000 \mathrm{rpm}$ and $80 \%$ engine load) and it was around $1.5 \%$ higher than that of diesel. The neat distilled water injection through modified SNCR gave approximately $6 \%$ reduction for all three test fuels. Moreover, the urea-water injection reduced the NO emission by $13 \%$ and $15 \%$ lower than diesel and biomixtures. These emission reductions are likely to be increased for $\mathrm{NOx}$ emission, as $\mathrm{NO}_{2}$ reductions would also contribute to the reduction [8].

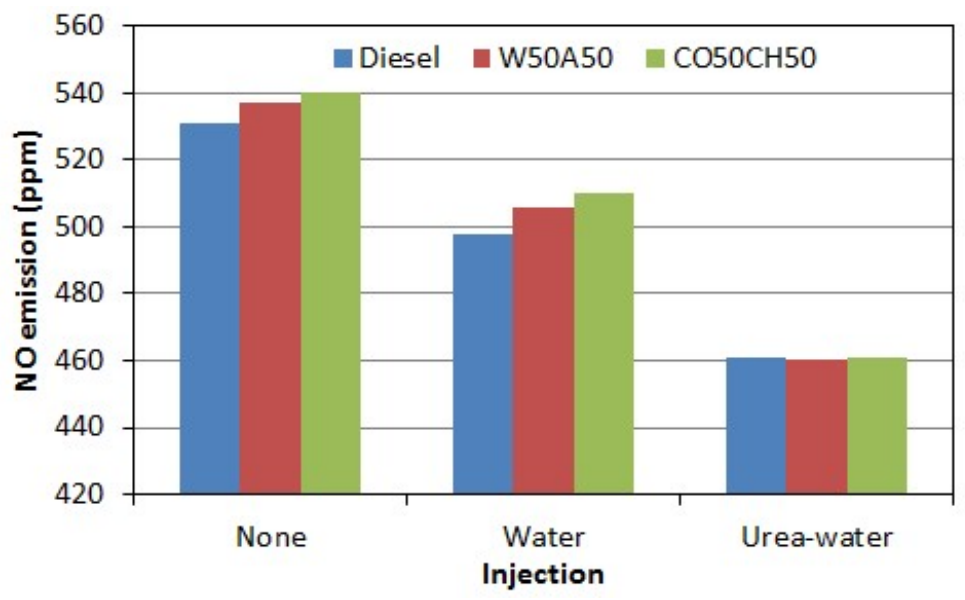

Figure 14. NO emissions of diesel, W50A50 and CO50CH50 with the modified SNCR application.

The modified SNCR aftertreatment system worked without any back pressure problem for low power density engine $(11.2 \mathrm{~kW}$ at the engine speed of $2000 \mathrm{rpm})$. The exhaust temperature was observed as $378^{\circ} \mathrm{C}$ which was well below conventional SNCR temperature window (between $875^{\circ} \mathrm{C}$ and $1050^{\circ} \mathrm{C}$ ) but above the lower limit of SCR $\left(350^{\circ} \mathrm{C}\right)$. Nevertheless, the desired exhaust emission of NO was successfully reduced by $15 \%$. These results proved that the idea of turbulence and residence time improvement through expansion pipe and swirl chamber was successful. Note that this value would be even higher for NOx emission if $\mathrm{NO}_{2}$ emission could be measured. It is also believed that designed aftertreatment 
technique would yield further reductions under higher exhaust temperatures with medium or high power density engines.

\section{CONCLUSION}

This study focused on NO emission reduction of biodiesels. The latest SCR and SNCR technologies found in literature were combined in a new design to enhance turbulence intensity and residence time. The main advantages of the new system were eliminating catalytic related problems such as weight, clogging, cost etc. The after treatment system was tested in the engine at $80 \%$ load with two injection agents which were neat distilled water and commercially available urea-water solution also known as AdBlue. The NO emission of biodiesels and diesel was reduced by approximately $6 \%$ and $15 \%$ by neat water and ureawater solution injections at $375 \mathrm{ml} / \mathrm{min}$ flow rate and at $378^{\circ} \mathrm{C}$ exhaust temperature. On the other hand, no significant effect of catalyst free modified SNCR system on $\mathrm{CO}, \mathrm{CO}_{2}$ and $\mathrm{HC}$ was observed. As a future work, effectiveness of the system can be tested for $\mathrm{NO}_{2}$ emission and unregulated $\mathrm{N}_{2} \mathrm{O}$ emission. Moreover, an advance control mechanism can be developed to minimise $\mathrm{NH}_{3}$ slip. To illustrate, if upstream NOx emission is measured simultaneously, then an adequate amount of injection fluid can be injected accordingly.

\section{ACKNOWLEDGMENT}

The work was supported by the Aston University $\mathrm{PhD}$ studentship and UKIERI project

\section{NOMENCLATURE}

CFD - Computational fluid dynamics

$\mathrm{CI}$ - Compression ignition

$\mathrm{CO}$ - Carbon monoxide

$\mathrm{CO} 2$ - Carbon dioxide

CO50CH50 - Cottonseed oil biodiesel and chicken fat biodiesel mixture (50/50 vol.)

$\mathrm{CO}\left(\mathrm{NH}_{2}\right)_{2}-$ Urea

DEF - diesel exhaust fluid

DOC - Diesel oxidation catalyst

DPF - Diesel particulate filter

$\mathrm{HC}$ - Unburned hydrocarbons

$\mathrm{NH} 3$ - Ammonia

$\mathrm{NO}$ - Nitrogen oxide

$\mathrm{NO} 2$ - Nitrogen dioxide

NOx - Nitrogen oxides

OEM - Original equipment manufacturer

SCR - Selective catalytic reduction

SNCR - Selective non-catalytic reduction

W50A50 - Waste cooking oil biodiesel and sheep fat biodiesel mixture (50/50 volume fraction) 


\section{REFERENCES}

1. Supriya B. Chavan, Meena Yadav, Reena Singh, Veena Singh, Rajendra R. Kumbhar, A. and Sharmab, Y. C. S., Production of Biodiesel from Three Indigenous Feedstock: Optimization of Process Parameters and Assessment of Various Fuel Properties, Environ. Sci. Technol. Vol. 36, pp 788-795, 2017.

2. Rajasekar, E. and Selvi, S., Review of Combustion Characteristics of CI Engines Fueled with Biodiesel, Renew. Sustain. Energy Rev., Vol. 35, pp 390-399, 2014.

3. Masera, K. and Hossain, A. K., Combustion Characteristics of Cottonseed Biodiesel and Chicken Fat Biodiesel Mixture in a Multi-Cylinder Compression Ignition Engine, SAE Tech. Pap. 2019-01-0015, Vol. 1, pp 1-14, 2019.

4. Sanjid, A., Kalam, M. A., Masjuki, H. H., Varman, M., Zulkifli, N. W. B. M., Abedin, M. J., Performance and Emission of Multi-Cylinder Diesel Engine Using Biodiesel Blends Obtained from Mixed Inedible Feedstocks, J. Clean. Prod., Vol. 112, pp 4114 4122, 2016.

5. Emiroğlu, A. O., Keskin, A. and Şen, M., Experimental Investigation of the Effects of Turkey Rendering Fat Biodiesel On Combustion, Performance and Exhaust Emissions of a Diesel Engine. Fuel, Vol. 216, pp 266-273, 2018.

6. Thangaraja, J., Anand, K. and Mehta, P. S. Biodiesel NOx Penalty and Control Measures - A Review, Renew. Sustain. Energy Rev., Vol. 61, pp 1-24, 2016.

7. Soleimanzadeh, H., Niaei, A., Salari, D., Tarjomannejad, A., Penner, S., Gtunbacher, M., Hosseini, S. A., and Mousavi, S. M., Modeling and Optimization of V2O5/TiO2 Nanocatalysts for NH3-Selective Catalytic Reduction (SCR) of NOx by RSM and ANN Techniques, J. Environ. Manage., Vol. 238, pp 360-367, 2019.

8. Tayyeb Javed, M., Irfan, N. \& Gibbs, B. M., Control of combustion-generated nitrogen oxides by selective non-catalytic reduction, J. Environ. Manage., Vol. 83, pp 251-289, 2007.

9. Yim, S. D. Kim, J. S., Baik, H. J., Nam, I., Mok, S. Y., Lee, J., Cho, B. K., and Oh, S. H., Decomposition of Urea into NH3 for the SCR Process, Ind. Eng. Chem. Res., Vol. 43, pp 4856-4863, 2004.

10. Muzio, L. J., Quartucy, G. C. and Cichanowiczy, J. E., Overview and Status of PostCombustion NOx control: SNCR, SCR and Hybrid Technologies, Int. J. Environ. Pollut., Vol. 17, 4-30, 2002.

11. Metkar, P. S., Balakotaiah, V. and Harold, M. P., Experimental Study of Mass Transfer Limitations in Fe- and Cu-zeolite-based NH3-SCR Monolithic Catalysts. Chem. Eng. Sci., Vol. 66, pp 5192-5203, 2011.

12. Bregge, C., Full-scale NOx reduction experiments at Norcem Brevik, M.Sc. Thesis, Telemark University College, 2014).

13. Hao, J., Yu, W., Lu, P., Zhang, Y. and Zhu, X., The effects of Na/K Additives and Flyash on NO reduction in a SNCR Process, Chemosphere, Vol. 122, pp 213-218, 2015.

14. Xu, M., Tu, Y., Zhou, A., Xu, H., Yu, W., Li, Z., and Yang, W., Numerical study of HCN and NH3 Reduction in a Two-Stage Entrained Flow Gasifier by Implementing Mild Combustion, Fuel, Vol. 251, pp 482-495, 2019.

15. Mansha, M., Qureshi, A. H. and Shahid, E. M., Prediction of Optimum Parameters for NOx Reduction Utilizing Selective Non-Catalytic Reduction (SNCR) Technique (Thermal DeNOx Process), Pakistan J. Eng. Appl. Sci., 2007.

16. Muric, K., Andersson, A., Andersson, L., Oom, K. and Group, V., The Potential of SNCR Based NOx Reduction in a Double Compression Expansion Engine, SAE Tech. Pap. 2018-01-1128, pp 1-14, 2018. 
17. Thiyagarajan, S., Geo, V. E., Martin, L. J. and Nagalingam, B., Selective Non-catalytic Reduction (SNCR) of CO2 and NO Emissions from a Single-Cylinder CI Engine Using Chemical Absorbents, Emiss. Control Sci. Technol. Vol. 3, pp 233-242, 2017.

18. Krahl, J., Tanugula, S. and Hopf, H., Diesel Fuel Additives to Reduce NOx Emissions from Diesel Engines Operated on Diesel and Biodiesel Fuels by SNCR, SAE Tech. Pap. 2010-01-2280, Vol. 1, 2010.

19. Yang, W., An, H., Li, J., Zhou, D. and Kraft, M., Impact of Urea Direct Injection on NOx Emission Formation of Diesel Engines Fueled by Biodiesel, in Proceedings of the ASME 2015 Internal Combustion Engine Division Fall Technical Conference, pp 1-7, 2015.

20. Haridass, M. and Jayaraman, M., Performance of Multi-Cylinder Diesel Engine Fueled with Mahua Biodiesel Using Selective Catalytic Reduction (SCR) Technique, Energy Sources, Part A Recover. Util. Environ. Eff., Vol. 40, pp 1910-1918, 2018.

21. Cho, C. P., Pyo, Y. D., Jang, J. Y., Kim, G. C. and Shin, Y. J., NOxreduction and N2O Emissions in a Diesel Engine Exhaust Using Fe-Zeolite and Vanadium Based SCR Catalysts, Appl. Therm. Eng., Vol. 110, pp 18-24, 2017.

22. Mehregan, M. and Moghiman, M., Effects of Nano-Additives on Pollutants Emission and Engine Performance in a Urea-SCR Equipped Diesel Engine Fueled with BlendedBiodiesel, Fuel, Vol. 222, pp 402-406, 2018.

23. Sachuthananthan, B., Balaji, G. and Krupakaran, R. L., Experimental exploration on Noxdiminution by the Combined Effect of Antioxidant Additives with SCR in a Diesel Engine Powered by Neem Biodiesel, Int. J. Ambient Energy, pp 1-12, 2018.

24. Gomez, M. F., Aftertreatment System Based on a Magnesium Hydroxide Injection to Reduce Carbon Dioxide Emissions From an Internal Combustion Engine, M.Sc. Thesis, Aston University Mech. Eng. and Des. Dept., Birmingham, 2018.

25. Yakhot, V., Orszag, S. A., Thangam, S., Gatski, T. B. and Speziale, C. G., Development of Turbulence Models for Shear Flows by a Double Expansion Technique, Phys. Fluids A, Vol. 4, pp 1510-1520, 1992.

26. Azimov, U., Eiji, T. and Nobuyuki, K., Combustion and exhaust Emission Characteristics of Diesel Micro-Pilot Ignited Dual-Fuel Engine, Long-Haul Travel Motiv. by Int. Tour. to Penang, Vol. i, pp 33-62, 2018.

27. Praveen, R. and Natarajan. N., Experimental Study of Selective Catalytic Reduction System on CI Engine Fuelled with Diesel-Ethanol Blend for NOx Reduction with Injection of Urea Solutions, Int. J. Eng. Technol. Vol. 6, pp 895-904, 2014. 